\title{
Editoriales
}

\section{Diabetes Mellitus, calidad de la atención y bioética}

En este número de A cta M édica Costarricense, dentro de la sección de artículos originales se encuentra el artículo de Adriana Laclé y col. sobre tamizaje de la retinopatía diabética en Diabetes Mellitus tipo 2 (DM 2). El trabajo permite comentarios en dos actividades del ejercicio de la medicina que han tomado gran relevancia en Costa Rica: la calidad de los servicios de salud y los aspectos bioéticos de la investigación con seres humanos.

Los autores identifican la DM 2 como " una enfermedad de alta prevalencia en el país..." con complicaciones que tienen "gran impacto en la autonomía de estas personas". Al revisar el artículo y proceder a su reflexión queda claro que estamos ante un problema de salud pública en Costa Rica, que es un determinante de la calidad de vida de quienes lo padecen al tener el potencial de producir complicaciones que llevan a discapacidad.

La retinopatía diabética es la complicación que lleva a perdida de la visión en el paciente con DM 2 y representa "la primera causa de nuevos casos de ceguera en adultos de 20 74 años". Por lo tanto la prevención de la ceguera o la detección temprana deben ser actividades de calidad en el manejo de los pacientes con DM 2 en todos los niveles de atención de la salud de los costarricenses.

¿Cómo justificamos entonces que en los 572 casos reportados por Laclé y col el $93 \%$ no tiene registrado un fondo de ojo en los dos últimos años de su control y que el $89 \%$ no tiene documentado ningún fondo de ojo en toda su historia de control en los diferentes niveles de atención? ¿Es este un fenómeno solo asociado al fondo de ojo o es de una falta de calidad total en la atención del diabético en Costa Rica?

¿Porqué?: ¿Faltan guías de atención para el paciente con DM2?, no hay equipo adecuado, hay negligencia de los médicos que tienen la responsabilidad de la atención de estos costarricenses, 0 bien es la combinación fatal del costarricense: negligencia, falta de recursos, excusas, ignorancia, mala preparación y mediocridad.

El estudio de Laclé y col, invita a la reflexión y a postular cambios en la atención del diabético. Es eficiente que el paciente reciba atención cerca de donde vive sin desplazamiento a San J osé, pero los médicos endocrinólogos e internistas deben definir claramente cuáles son los términos de calidad de la atención que estos pacientes deben recibir y cuáles son las auditorias a dichos parámetros que se deben establecer y quienes son los responsables de ejecutarlas.
El otro aspecto que el artículo permite comentar es sobre la bioética de la investigación con seres humanos. El tema ha sido tratado por los periodistas en repetidas ocasiones, pero es interesante el hecho de que no ha sido tema de debate entre los médicos. La J unta de Gobierno del Colegio de M édicos y su presidente el Dr. E duardo Flores han dejado claro, con sus opiniones, que no hay tolerancia hacia las transgresiones a los principios bioéticos. El país se ha organizado a nivel nacional con el Consejo Nacional de Investigación sus leyes y reglamentos, a nivel de la Caja Costarricense de Seguro Social con sus Comités de Bioética e Investigación y a nivel universitario con los respectivos grupos en la U niversidad de Costa Rica y en la Universidad de Ciencias M édicas, para proveer el marco legal, las reglas de juego y los límites de una actividad fundamental para la medicina costarricense, como es la investigación clínica y experimental con seres humanos.

La generación de nuevos procedimientos, nuevos tratamientos y el conocimiento de las causas y consecuencias de la enfermedad no serían posibles sin la investigación en el sujeto humano. En el artículo que comentamos el proceso de investigación identifica defectos en la atención médica de los costarricenses.

Un principio básico del respeto al sujeto de investigación es el hecho de que independientemente de la calidad de atención que este recibiendo o de los beneficios sobre su salud que nosotros percibamos que va a recibir como participante de la investigación, no podemos evitar que le debe quedar claro que es un sujeto de investigación y que está participando en una investigación. La forma más efectiva de cumplir con este precepto y de documentarlo es el consentimiento informado.

La mayoría de los médicos tienen claro el concepto de consentimiento informado; sin embargo, cuando intervienen como investigadores no saben cuáles son los parámetros para escribir su texto, o la técnica para aplicarlo o quien debe aplicarlo. Tienden a evitar dentro de lo permitido el tener que obtener un consentimiento informado de los sujetos de investigación en su proyecto.

Entonces la investigación de Laclé y col. cumplió adecuadamente con la revisión del Comité Ético Científico de la U niversidad de Costa Rica, sin embargo, es un ejemplo de que a pesar de que detectaron una falla en la atención de los casos, su intervención con fondo de ojo e identificación de cada uno de los sujetos al contactarlos requería un consentimiento informado, al transformar al individuo de 
paciente en un sistema de salud a sujeto de investigación en un proyecto con objetivos y actividades de investigación.

A cta M édica Costarricense desea ser parte del concepto de cero tolerancia a la investigación clandestina en seres humanos en Costa Rica y ha establecido como requisito la demostración por parte de los investigadores de la aprobación por un comité de investigación acreditado de los proyectos que originan lo artículos científicos originales que se le ofrecen para publicación.

El Dr. Flores ha expresado la disponibilidad de llevar más lejos esta iniciativa exigiendo la evidencia de aprobación de un comité de investigación acreditado a todos los trabajos libres que se presenten en el Congreso M édico Nacional.
El objetivo del quehacer médico que apoya el Colegio de M édicos y Cirujanos y el Comité editorial de Acta M édica Costarricense es contribuir a la atención médica de la mejor calidad para los costarricenses y apoyar la investigación clínica dentro de un marco bioético con apego absoluto al respeto del ser humano que participa como sujeto de investigación.

Oscar Porras

J efe, Servicio de Inmunología y Reumatología Pediátrica.

Hospital Nacional de Niños "Dr. Carlos

Sáenz Herrera".

Miembro de la Comité Ético Científico. U niversidad de Costa Rica. 